\title{
Evaluating Strategic IT Investments: An Assessment of Investment Alternatives for a Web Content Management System
}

\author{
Petri Hallikainen, Hannu Kivijärvi, Kari Nurmimäki \\ Helsinki School of Economics and Business Administration, \\ P.O. Box 1210, 00100 Helsinki, Finland, \\ E-mail: Petri.Hallikainen@hkkk.fi, Hannu.Kivijarvi@hkkk.fi, k11312@ky.hkkk.fi
}

\begin{abstract}
As widely recognized in the literature, information technology (IT) investments have several special characteristics that make assessing their costs and benefits complicated. Here, we address the problem of evaluating a web content management system for both internal and external use. The investment is presently undergoing an evaluation process in a multinational company. We aim at making explicit the desired benefits and expected risks of the system investment. An evaluation hierarchy at general level is constructed. After this, a more detailed hierarchy is constructed to take into account the contextual issues. To catch the contextual issues key company representatives were interviewed. The investment alternatives are compared applying the principles of the Analytic Hierarchy Process $(A H P)$. Due to the subjective and uncertain characteristics of the strategic IT investments a wide range of sensitivity analyses is performed.
\end{abstract}

\section{Introduction}

During the last decades more than half of firms' capital budgets are being spent on building and refreshing information technology (IT) applications and other IT infrastructure [51]. At the same time IT investments enhance the productivity, profitability, competitiveness, effectiveness, performance, success, satisfaction, etc. at global, national, industrial, organizational, and individual levels $[52,33,4,47,25,24,23,2,8]$. At the outset it would seem that the investments in IT resemble other investments with respect to costs, payoffs, as well as planning methods. This view is generally accepted in capital budgeting literature (see [10]) and it might hold true with IT investments at operational levels in some special occasions. However, investments in strategic IT at organizations may differ considerably from the rest of investments.

Any information technology has strategic value if it assists an organization to create its strategic objectives or supports to realize them. Generally, an IS has strategic power if it helps an organization to gain competitive advantage, to improve productivity and performance, to enable new ways of managing and organizing, or to develop new business. Strategic information systems are companywide, a number of people are involved in the development and use of those systems, the benefits of those systems are elusive, and they make possible to create new organizational forms like partnerships and networks. The closer IT fits the characteristics of strategic planning and decision making, the greater its strategic value.

The research problem in this paper is the evaluation of strategic information systems. The problem is not new and the relevant literature offers enormous number of classifications, partial conceptualisations, reviews, and characterizations and descriptive analyses of the problem. In addition, in the relevant literature there are a variety of appraisal and measurement methodologies and techniques that can be employed in justifying and evaluating IT investments. Some of those techniques are general and some IT specific. Adler [1] evaluates the traditional appraisal techniques of strategic investments and proposes following alternative methods: strategic cost management, multiattribute decision model, value analysis, analytical hierarchy process, R\&D method, and uncertainty method. Molnar and Sharda [35] classify the strategic/IT investment evaluation methods into three groups: objective, subjective, and integrated methods. Wen and Sylla [53] review the existing IT investment evaluation methods and categorize them into three groups: IT evaluation methods for tangible benefits (return on investment, cost-benefit analysis, return on management, information economics), intangible benefits (multi objective-multi criteria, value analysis, critical success factors), and risks (real option, portfolio analysis, Delphi approach).

Based on this knowledge we know that strategic IT investments are difficult and controversial to manage, intangible to measure, risky, and the possible failures can cause serious problems in organizations. In addition we know that there are a variety of appraisal and measurement techniques that can be used. However, each of those evaluation techniques has some serious deficiencies that prevent its common use and calls for additional efforts to develop new methods. Those deficiencies include, among others, the following aspects:

- Method is not used or is used only in a specific case (developed for academic merits only)

- Is largely used, like ROI, but requires unrealistic assumptions, or is inflexible to use

- Is too complicated for practice

- Requires special software that is not generally available

- Has deficient theoretical background

As an answer to the above critique, we need

1. A theoretically sound framework for the evaluation of strategic IT investments.

2. Methodology based on that framework.

3. A concrete investment support system to help decision makers. 
The purpose of this paper is to fulfill these three requirements. In section two, we conceptualize the key characteristics of strategic IT investments and in section three we launch a theoretical framework for evaluating those investments. In section four, the theoretical principles are implemented within an actual case where an investment in a Web Content Management system for a multinational banking and insurance corporation is analyzed.

\section{Justification and evaluation of strategic IT investments}

Any investment decision is an irreversible commitment of resources made in expectation of uncertain future gains. Essential characteristics of an investment decision are the substantial commitment of resources, and the fact that the benefits are not wholly exhausted in the short term. Both the short-term profitability and the long-term well-being of the company are based on the company's investments. Investments can be made in the company's tangible assets like plant and equipment or intangible assets like information systems, logistics systems, know-how, patents, goodwill, brands, etc.

Strategic investments as opposed to necessity investments and investments in productivity improvements are an instrument to implement corporate strategies and they have, for example, the following properties:

1. They are necessary for the survival and well-being of the corporation

2. They are corporate-wide, even global, and they have significant direct and indirect impacts on multiple functions

3. They are goal and objective oriented but the goals and objectives may be controversial

4. They are expensive and tie a lot of organizational resources

5. They cover a long time frame

6. They are tangible and intangible by nature

If compared to other investments in business context, strategic IT investments have some special characteristics making it difficult to evaluate their costs - and especially their benefits. First, the benefits are mainly intangible in nature [38]. Second, the benefits of strategic IT investments are often realized during a long period of time. Thus, using only traditional investment evaluation techniques for evaluation is not sufficient. Most of the traditional investment criteria imply that the initial investment, the incremental cash flows, cost of capital, and the economic time horizon of the investment alternative are known. It is assumed that all the effects of the investment can be traced, measured, and transformed into monetary units. Intangible costs and revenues are assumed to be zero and subjective criteria are ignored. Moreover, at least part of the risks in IS investments are exogenous and uncontrollable [7].

In practice examples of ad hoc management of technology projects are frequently found (e.g. [22]) and at the same time the lack of a systematic evaluation practice is seen as a difficult problem by companies [19]. What is promising, however, is that if IT investments are evaluated, there is empirical evidence of a positive relation between IT evaluation and alignment of IT with the business strategy [46].

Especially adoption of Internet-based technologies by companies to be used for various purposes in conducting business processes is seen strategically essential or even necessary. There is, however, contradictory evidence about the profitability of IT investments $[5,6]$ in general. Particularly in the case of "new technologies" like different network based technologies the rationale for making the investments cannot be clearly expressed because of the uncertainty in future developments of technology and business environments. In the organizational theory literature it is argued that the dominant designs in technology are usually only known in retrospect [48]. Thus, managers have to make decisions on investing in new technologies in highly uncertain environments where technological experts are eager to speak for the new technological innovations.

The arguments describing the potential value of the technology investments may stem from the technological solution (technology push) or from the business problems (business pull) [9]. In many cases IT investments are seen as sources of competitive advantage [23, 2, 8] and in some cases information systems form the basis for conducting core business processes in companies [18]. IT should be understood as a major capital asset, because of its potentially wide organizational effects and the large expenditure on it (estimated by WITSA [11] to have passes 2 trillion USD worldwide in 1999). Thus, the strategic potential and value of IT investments are constantly increasing.

Mirani and Lederer [34] identified three sub-dimensions of strategic benefits: competitive advantage, alignment, and customer relations. They maintained that competitive advantage benefits help companies introduce radical changes to business processes and understood alignment broadly to directly support organizational goals, help the organization to create linkages with other organizations, or enable it to respond faster to environmental changes [34].

When evaluating strategic IT investments it is recommended to somehow rank alternatives, although precise values could not be used, and to conduct sensitivity analyses [8]. Since making decisions on strategic IT investments requires thorough understanding about organizational processes and competitive situation, different stakeholder groups should be involved in the evaluation process so that the different views of the system are acknowledged [14, 34]. Recently, the importance of bringing the so-called tacit knowledge into organizational decision making has been stressed in the literature [36]. It is a great challenge for the research community to develop methods and procedures for this purpose.

Some suggestions how to evaluate IT investments have been presented in the literature (e.g. [50]). The different approaches have been analysed by Wehrs [50] using a twodimensional framework including the dimensions of the time frame and level of aggregation. Marchewka and Keil [29] identified four basic approaches for selecting IT projects: cost/benefit analysis, scoring or ranking models, management science models, and the portfolio management approach. Moreover, Dos Santos [12] proposed an option pricing model for determining the value of new technology investments to take into account the value of the future investments made possible by the initial investment. Adler 
[1] assessed the traditional appraisal techniques of strategic investments. He offers following alternative evaluation methods: strategic cost management, multiattribute decision model, value analysis, analytical hierarchy process, R\&D method, and uncertainty method. Wen and Sylla [53] review the existing IT investment evaluation methods and classify them into three groups: IT evaluation methods for tangible benefits (return on investment, cost-benefit analysis, return on management, information economics), intangible benefits (multi objective-multi criteria, value analysis, critical success factors), and risks (real option, portfolio analysis, Delphi approach). On the other hand, Molnar and Sharda [35] organize the strategic IT investment evaluation methods into three groups: objective, subjective, and integrated methods.

Smithson and Hirschheim [45] pointed out that subjectivity is included in even the most formal approaches to IS evaluation. Moreover, Mirani and Lederer [34] maintained that no single theory or measuring instrument can be expected to capture all aspects of IS benefits in every context. Every evaluation method has its advantages and disadvantages. A summary of these can be found in Wen and Sylla [53].

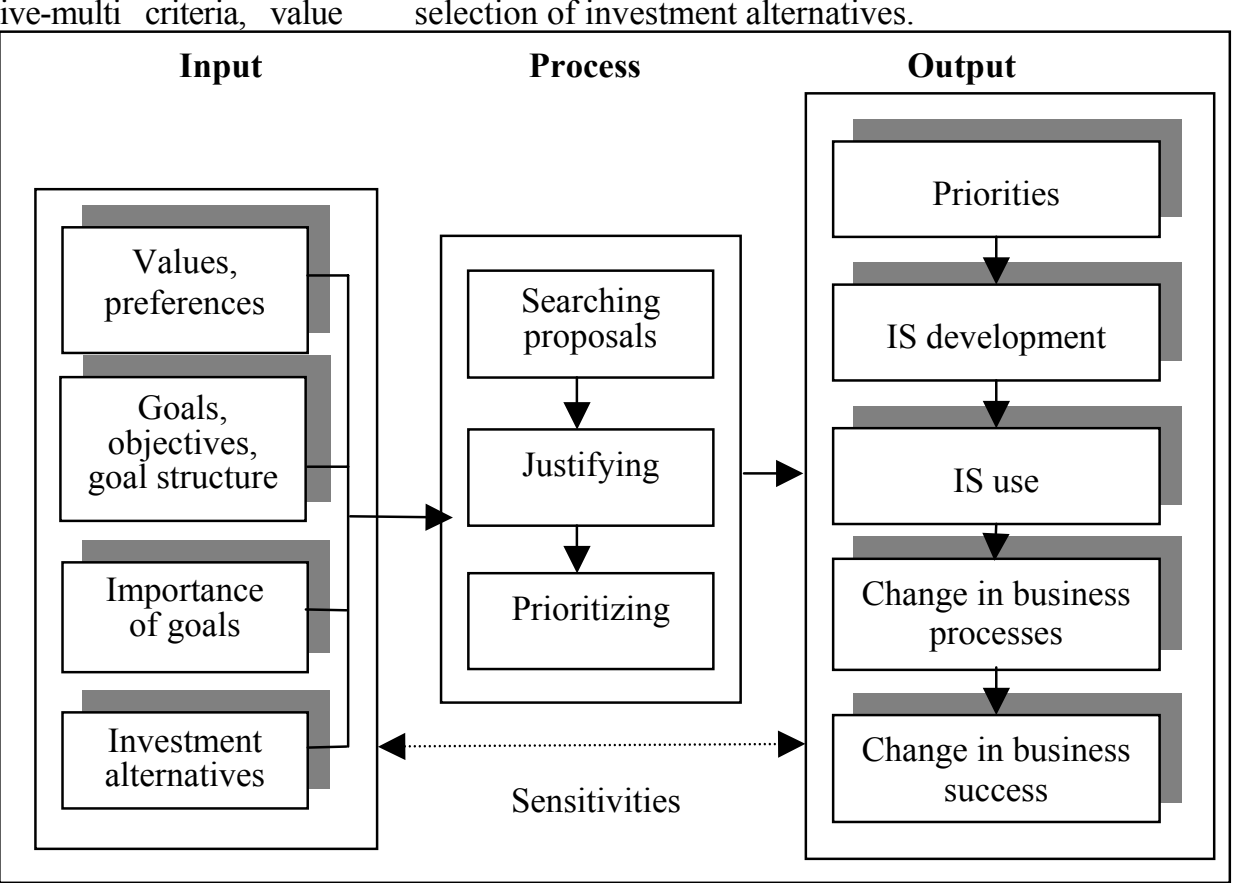

We argue that a more holistic approach for evaluating strategic IT investments is needed. This kind of approach can consist of a theoretical framework that forms the foundation for the evaluation, and of a general decision making methodology, such as the AHP-methodology.

Although all investments are risky to some extent it is clear that any feature of strategic investments discussed above cannot be supported by simple, straightforward analyses but they call for a versatile set of wealthy sensitivity analyses. "Sensitivity analysis measures the impact on project outcomes of changing one or more key input values about which there is uncertainty" [31]. Versatile set of sensitivity analyses is one of the key requests for the support of the intangible investment decisions.

\section{Conceptual foundations: framework and methodology}

\subsection{A framework for evaluating strategic IT investments}

Based on the above discussion about the characteristics of strategic IT investments we propose a framework for evaluating strategic IT investments as presented in Figure 1.

Any strategic investment process employs individual and organizational values and preferences, goals and objectives and, of course, decision alternatives as an input. The output of the strategic investment process may have wide organizational effects and the success is finally measured by the same measures as business success in general. The subsequent effects of the prioritization decision are discussed only briefly here, since the actual research problem of the present study is restricted to the selection of investment alternatives. 
In organizational context, "organizational value systems provide guides for organizational goals, policies, and strategies" [54]. Organizational values (value system) guide companies to make strategic choices, set goals and objectives, or run the everyday business. Personal and organizational values have multiple implications for the different phases of the strategy process. Values influence on the search of investment alternatives, they manifest in the goals and goals structure, and they are present when the alternatives are evaluated. Although the values are relatively fixed they may change even in short run, or at least they can be explicated differently.

\subsubsection{Goals, objectives and goal structure}

According to the general portfolio (investment) theory by Markowitz [30] all investors are maximising their expected utility. The expected utility of an investor is assumed to depend only on the expected value and variance of the expected return.

Thus, in general, the expected value is a valid measure of return and the variance provides a valid measure of risk and every investment decision is completely described by these two measures. Therefore the main goal in our framework is the 'IS project utility' (second column in Table 2).

In practice the final measure of the IT investment efficiency or effectiveness can be called by different terms, like Success of IS project or System effectiveness [16]. Every investment in an organization should contribute to the goals of that organization. Nowadays IT investments are closely related to the development of business processes and this should be taken into account in evaluation. The IS project utility, or success, might be described as the extent to which the expected benefits have realized and whether the development process has proceeded according to plans. In the investment initiation phase evaluation concerns the assessment of the expected benefits to be gained from the investment, i.e. the assumed utility to be realized in the future.

The second level criteria in our model are return and risk [30]. These criteria are widely accepted as a basis for the evaluation of any portfolio of investment alternatives. However, in IT context we cannot directly measure the financial return of the investment or its risk by variance as the original theory suggest. Instead we have to use surrogate measures at the third level.

At the third level in our model, it is logical to divide return to costs and benefits. In some special case it is possible to differentiate and measure the benefits of the IT investments in financial terms but in most cases the benefits gained from information system investments are intangible and very difficult to express in monetary terms [38]. In addition, the measurable benefits are most often only costs savings. Therefore, in our model we divide the return into two subgoals: costs and intangible benefits.

The concept of risk has been identified in various ways in the literature [28]. In our model, we divide risk at the general level to systematic and unsystematic. Systematic risk stems from outside of the company and unsystematic from inside of the company [44].

At the fourth level of our model, we divide the intangible benefits further into business impact, strategic value and success of use (adapted from [27, 34]). Success of use refers to the usability of the systems and business impact to the actual effects on conducting the business processes. Strategic value refers to such dimensions as competitive advantage or organizational learning. This classification is in line with other classifications and empirical evidence found in the literature. The empirical findings of Lederer and Mirani [27] identified business redesign, improved information and strategic value as the most important sources of benefits from information technology investments. In their later work, Mirani and Lederer [34] confirmed the earlier work of Weill [52] that the organizational benefits of information systems can be classified into three dimensions: strategic, informational, and transactional. Mirani and Lederer [34] divide strategic benefits further to competitive advantage, alignment and customer relations; informational benefits to information access, information quality, and information flexibility; and transactional benefits to communications efficiency, systems development efficiency, and business efficiency.

The successful use of the system has been addressed in many studies about user information satisfaction [4, 17]. Moreover, we divided the costs into business costs and IT costs.

We considered the software development uncertainty factors and the notion of the magnitude of potential loss in the case of implementation problems proposed by Barki et al. [3] an appropriate basis for assessing unsystematic risks in our study. The criteria are technological novelty, application size, expertise, application complexity, and organizational environment. A more detailed description of the criteria is given in Table 2.

More hierarchical levels could be added toward more general or more specific directions in the model. We believe that the additional levels are more contexts specific and are discussed in section 4 with the case. The criteria in the first three levels are probably relevant in making decisions on most information technology investments, but some of the criteria on level four might be relevant for some investments but not for others.

\subsubsection{Alternatives}

When investing in the information systems a company has the "make-or-buy" decision to make. Basically there are three alternatives: software package, tailored package or inhouse development.

According to Heckman [20] the procurement processes have changed from an internal to market-oriented processes. Even systems having wide impacts on organizations are purchased from outside of the company. Typical examples of this trend are the acquisitions of ERP and CRM systems. Because of the wide impacts this type of systems have on organizations the different procurement alternatives have to be carefully assessed so that all the benefits and effects of the system are recognized. In practice, however, in many cases financial considerations only are dominating the decision process.

\subsubsection{Investment process}

In general, the investment, or the capital budgeting process consists of separate phases. According to Pike and Neale [37] capital budgeting includes the following activities: Determination of the budget, Search for, and 
development of projects, Evaluation and authorization, and Monitoring and control. McIntyre and Coulthurst [32] used the following three-phase model: The Creation Phase, The Decision Phase, The Implementation Phase. According to Shank [43] the strategic investment process consists of the following phases: identifying spending proposals, the quantitative analysis of the incremental cash flow, assessing qualitative issues that cannot be fitted into cash flow analysis, and making a 'yes' or 'no' decision. These classifications are general enough to cover conventional as well as intangible investments. The divergence of the phasemodels finally led us to use a more general process-model: Searching proposals, Justifying, and Prioritizing.

\subsubsection{Output: implementation process}

Strategic investments have wide and long-lasting effects in the organization. The primary output of the decision process is the prioritised alternatives. The best possible alternative is chosen for buying / development. After installation, the system is used which might change the business processes and business success. When evaluating the effects of strategic IT investments, these indirect effects have to be evaluated as well.

The procurement alternatives differ in terms of control management can exercise over the development process. In the production phase some corrections or tailoring may need to be conducted. It has to be noticed that commitment to a certain procurement alternative may tie the company to the limited ways of conducting business processes. In the long run, this may even affect the company's competitiveness.

\subsubsection{Sensitivity analyses}

Analyzing strategic investments is a challenging task because all relevant inputs are subject to uncertainty and equivocality and they are based on qualitative and quantitative data, subjective judgements, and conflicting goals. Values, preferences and goals - even alternatives are not unambiguous but they can be re-evaluated, ordered differently, described in more details, etc. There is no single, exact way to solve strategic investment problems or single solution to the problem. follows: "Sensitivity analysis measures the impact on project outcomes of changing one ore more key input values about which there is uncertainty." Generally sensitivity analysis shows the critical inputs and it can be performed experimentally or analytically depending on the problem formulation.

Because the strategic investment decisions have a wide range of outputs the sensitivity analyses can also be performed at different levels. It is essential to know if the priorities of the alternatives are sensitive to the change of one or more input items. However, it is much more important to know if the alteration of input items have any impact on the IS development, IS use, business processes, or business success. In other words, the significance of the sensitivity is increasing in line with the scope of the output measurement. In Table 1, the increasing degree of the sensitivity is described.

\subsection{A potential methodology: Reduced Analytical Hierarchy Process}

One potential methodology to evaluate IS investments is to measure their impacts by the utility concept as concretized by the principles of Analytic Hierarchy Process $[40,41]$. AHP is a general decision-making tool that can be used to evaluate discrete alternatives, which may include subjective or intangible criteria [41]. By AHP it is possible to structure the decision problem into a hierarchy that reflects the values, goals, objectives, and desires of the decision-makers. AHP is developed at the beginning of seventies to tackle complex, multivalued, political and economic decision problems. Thus, AHP fits the strategic investments problems and the framework of this study.

As input, AHP uses the judgements of the decisionmakers about the alternatives, evaluation criteria, relationships between the criteria (importance), and the relationships between the alternatives (preference). In the evaluation process subjective values, personal knowledge, and objective information can be linked together. As an output, the goal hierarchy, the priorities of alternatives and their sensitivities are reached.

The main advantage of the AHP approach is that the different criteria with divergent measures can be transformed easily into a single utility measure. The key conceptual tool of AHP is the goal hierarchy where the relations between the goals are described. The additive aggregation rule behind the hierarchy makes it easy to understand the principle of the

\section{Table 1 Degree of sensitivity}

Sensitivity analysis forms an important part of assessing strategic (intangible) investment, not least because it offers a means of examining the input uncertainty related to the output. Marshall [31] defines the sensitivity analysis as decomposition and the results.

In IS-literature, Santhanam and Guimares [42] applied AHP to the problem of evaluating the quality of institutional Decision Support Systems. Wen and Sylla [53] developed an hybrid model where AHP is integrated into a goal 
programming model in order to quantify subjective intangible benefits and risk factors involved in IT investments. In addition, Lai et al. [26] applied AHP to the selection of a multimedia authoring system. there can be tens or even hundreds potential software alternatives available. The pairwise comparison in full extent would be a frustrating and time consuming process. Therefore, a preliminary reduction routine is needed to shorten the AHP-process. Within IT investment decisions, a

\begin{tabular}{|c|c|c|c|c|c|}
\hline $\begin{array}{l}\text { Goal } \\
\text { Class }\end{array}$ & & General & $\leftrightarrow$ & Semicontextual & Contextual \\
\hline \multirow[t]{13}{*}{$\begin{array}{l}\text { Goal } \\
\text { level }\end{array}$} & $\begin{array}{l}\text { Main } \\
\text { goal }\end{array}$ & $\begin{array}{l}\text { 2. level } \\
\text { goal }\end{array}$ & 3. level goal & 4. level goal & 5. level goal \\
\hline & \multirow{12}{*}{$\begin{array}{l}\text { IS } \\
\text { Project } \\
\text { Utility }\end{array}$} & \multirow{5}{*}{ Return } & \multirow{2}{*}{ Costs } & Business costs & $\begin{array}{l}\text { Aminstration costs } \\
\text { Coordination costs }\end{array}$ \\
\hline & & & & IT costs & $\begin{array}{l}\text { Continuous } \\
\text { One-off }\end{array}$ \\
\hline & & & \multirow{3}{*}{$\begin{array}{l}\text { Intangible } \\
\text { benefits }\end{array}$} & Business impact & $\begin{array}{l}\text { Business efficiency } \\
\text { Group work support }\end{array}$ \\
\hline & & & & Strategic value & $\begin{array}{l}\text { Business integration } \\
\text { Learning about SD } \\
\text { Learning about technology }\end{array}$ \\
\hline & & & & Use & $\begin{array}{l}\text { Administrative efficiency } \\
\text { Ease of learning } \\
\text { Ease of use }\end{array}$ \\
\hline & & & Systematic & Adaptation requirements & --- \\
\hline & & & & Vendor experience & \\
\hline & & & & Application complexity & $\begin{array}{l}\text { Technical complexity. } \\
\text { Number of links to existing other } \\
\text { systems. } \\
\text { Number of links to future systems. }\end{array}$ \\
\hline & & & & Application size & $\begin{array}{l}\text { Number of people on development } \\
\text { team. } \\
\text { Relative project size } \\
\text { Diversity of people in the } \\
\text { development group. } \\
\text { Number of users in the organization. } \\
\text { Number of hierarchical levels } \\
\text { occupied by users. }\end{array}$ \\
\hline & & Risks & Unsystematic & Organizational environment & $\begin{array}{l}\text { Extent of changes brought by the } \\
\text { system. } \\
\text { Resource insufficiency. } \\
\text { Intensity of conflicts between the team } \\
\text { members and between users and the } \\
\text { team members. } \\
\text { Clarity of role definitions. } \\
\text { Task complexity. }\end{array}$ \\
\hline & & & & Team expertise & $\begin{array}{l}\text { Development expertise in team. } \\
\text { Team's expertise with the application } \\
\text { type. } \\
\text { Team's expertise with the task. } \\
\text { Team's general expertise. } \\
\text { User experience and support. }\end{array}$ \\
\hline & & & & Technological novelty & $\begin{array}{l}\text { Need for new hardware and software. } \\
\text { Number of hardware and software } \\
\text { suppliers. } \\
\text { Number of users outside the } \\
\text { organization. }\end{array}$ \\
\hline $\begin{array}{l}\text { Theory } \\
\text { base }\end{array}$ & Mark & witz [30] & $\begin{array}{l}\text { Powell [38] } \\
\text { Hochstrasser [21] } \\
\text { Ward et al. [49] } \\
\text { Shapiro [44] }\end{array}$ & $\begin{array}{l}\text { Baroudi and Orlikowski [4] } \\
\text { Clemons [8] } \\
\text { Lederer and Mirani [27] } \\
\text { Mirani and Lederer [34] } \\
\text { Barki et al. [3] }\end{array}$ & \\
\hline
\end{tabular}

\section{Table 2 A goal classification for evaluating IS project success}

A disadvantage of APH methodology is the extent of the pairwise comparisons when there are a large number of items to be compared. When evaluating IT investments great number of alternatives can be restricted by setting technical thresholds which the alternatives have to exceed at minimum in order to be considered as a 'finalist'. In addition, when the evaluation of the technical requirements is separated also the number of criteria in the goal hierarchy is decreased. 
Because the proposed framework is general an alternative way to shorten the evaluation process is to use other multiattribute weighting techniques (MAUDM, MAUT, SMART, SMARTER) to implement this framework.

\section{Case: supporting the selection of a web content management system}

\subsection{Case organization}

The case organization selected for this research is a multinational company in the finance services field. The company has experienced many structural changes over the last ten years. The number of employees has recently grown to well over 30000 . Being a member of the top tier as to market share and possessing several cutting edge technology financial products, the demands of integrating the corporate members are increasing. These demands stem from customers, who would rather see the corporation as one single supplier across borders. They also stem from within, mainly articulated in terms of increased synergies. One vehicle conceived as an enabling, integrating strategic factor is the company's WWW-based network environment.

Whereas the company is presently faced with a wide selection of related software and solutions in creating intranet and extranet content, the overall purpose is integration. In more precise terms, the company pursues reducing the number of content creation environments, separate (partly custom developed) content management systems, and the number of sites. In this pursuit, the key issues are as follows. Firstly, the company aims at setting up one central, packaged, WCM (Web Content Management) system available for all portfolio members. Secondly, the company wishes to strengthen its identity by providing a unified set of preprogrammed artifacts in the form of symbols, labels, logotypes and layout structures, which are easily replicated and reused.

The third key issue is making the content creation and publication directly available to individual business units. In today's system environment a business unit, at the outset, typically drafts a content document. This effort will be multiplied if counter-party units in other countries also wish to draft a version of their own. There follows perhaps several rounds of reviews (times the number of content producers). Eventually one version is selected in an approval process, which again may take several rounds. Finally the document is ready for publishing, and it is delivered to the chief editor - sometimes called WEB Master. The remaining source of anxiety is the timing of publication, if there is a backlog of material queuing up. A centralized WCM is the contemporary answer for streamlining such a process. Presently, creation, approval, testing and publication procedure is judged to be cumbersome, as illustrated above. In particular, the testing and publication phases rely on a few technically oriented persons stationed apart from each other in portfolio countries. This, naturally, leads to coordination costs that could be eliminated with a centralized WCM system.

The last issue is considered to be of utmost importance and far reaching as to its consequences. Thus, the system is regarded as having strategic level benefits in terms of integrating business processes and streamlining the webpublication process.

\subsection{Alternatives for the web content management}

WCM's essentially comprise a set of software with the following basic purposes in an organizational context: facilitating creation of static or dynamic content, reviewing and approving of the content, publishing and delivering of the content, and (possibly) version control, as well as archiving. From an IS category perspective their relative importance has markedly risen during the last few years along with enterprise resource planning systems. The rising trend in interest towards WCM's can be traced to timing, cost and quality considerations. Specific problem areas relate, among others, to delays in publishing, erroneous or out-of-date content and pressures on staff and infrastructure associated with web environment.

At the outset, a set of ten WCM packages was identified. This process was supported by published reports and analysis of international consultancy companies. The ten initial candidates were submitted to desktop analysis, with foci on functional requirements and compatibility with the existing IT architecture. Together, they do not constitute a rigid, filter-type of screening mechanism. Rather, they tend to support preparation of system selection proposals as a set of checklist. This early screening aims at reducing the number of candidates to a few finalists. Due to its relatively large size the company adheres to a reduced set of standards as to platforms and infrastructure in general. Thereby the checklist requires a description of platform fit, with a view to reducing tailoring needs and eliminating risks of noncompatibility. Another checklist item of great weight is the scalability of the system. This aims at reducing risk of unforeseen additional investments. The analysis led to the selection of four final contenders: Vignette V/5 e-business platform, IBM Content Manager, Interwoven 4.5 and Documentum 4i, v. 4.1.

\subsection{Data collection: Final goal hierarchy and preferences}

We adapted the goal hierarchy presented in section 3.1.2 for conducting the selection of the alternatives in the case described in the previous sections. The general goal hierarchy was expanded to include case-specific, contextual goals and measures. This was done by interviewing the key company representative of the caseproject, who was the person responsible for making the investment proposal to the management. After determining the goals, the alternatives were compared and the weights of the goals were determined using questionnaires. The respondent evaluated the weights of the goals by first determining the order of the importance and then determining the strength of the importance. In a similar way, the respondent conducted a pair-wise comparison of the investment alternatives with respect to every measure in the model. Through the evaluation process the contemplated members of the upcoming project team 
supported him. Documents drafted during desktop analysis were available. He was further supported by the standing procedural instructions of the company relating to IT selection and criteria to be applied. The researchers ascertained that the research subject understood the meanings of the general goals and measures used in the study by briefing the respondent in person and being on permanent stand-by throughout.

The final goal hierarchy and the respective measures are shown in Table 2.

\subsection{Results}

\subsubsection{Priorities}

After making all paired comparisons according to the principles of AHP (alternatives with respect to all lower level criteria and all criteria with respect to upper criteria) it is possible to compute the total priorities of alternative strategies (Figure 2). Documentum seems to be the best alternative with respect to the goal hierarchy discussed above. The ranking of the alternatives can be scrutinized in details by following the structure of the developed hierarchy. For example at the lowest level, 'Business efficiency' contributes most significantly to all strategic alternatives. On the other hand, 'Business integration' seems to be the second biggest advantage to the other strategies except Content manager that has relatively low 'Continuous costs'.

Documentum and Vignette are efficient Pareto solutions to the initial investment problem. Thus, by selecting among those three alternatives the decision maker can maximize the return and minimize the risks. Content Manager and Interwoven can be rejected because more efficient alternative can always be found no matter how the return and risk are weighted (other things being equal).

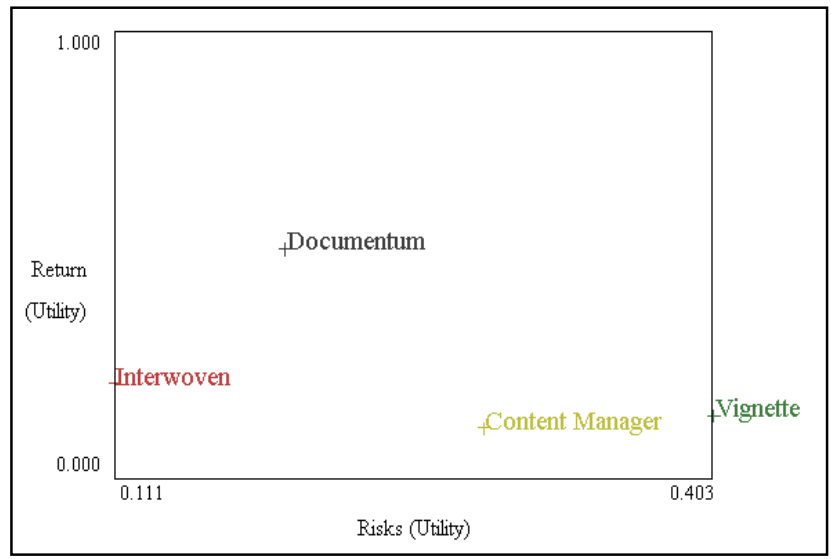

Figure 3 The portfolio of investments alternatives

\subsubsection{Sensitivities}

Using sensitivity analysis we can study how sensitive the priorities of the alternatives are to the changes in input data, i.e. the importance of the criteria. For example Figure 4 shows the sensitivity analysis of the results with respect to the importance of 'Intangible benefits' goal. The graph shows that the current weight of the criterion is 0.75 (vertical line). The height of the intersection of this vertical line with alternative lines shows the priorities of the alternatives. In the initial solution Documentum is the most preferred strategy. If the 'Intangible benefits' goal becomes less important then Content manager strategy would be the preferred alternative. For example if 'Intangible benefits' and 'Costs' were weighted

Figure 2. Final ranking of the content management strategies with lowest stacked bars

When all strategies are analysed the final results can be grouped into a portfolio matrix (Figure 3 ). The position of each alternative in the matrix is determined directly by the coefficients of risk and expected return as suggested by the original investment theory [30]. According to Figure 3, only equally, then Documentum and Content manager would be prioritized almost equally.

Because the input data is quite subjective it is important to study the dynamics of the sensitivities carefully. If, for example, the weight of the 'Intangible benefits' is decreased to 30 percent the ranking of the alternatives is changed. Because all criteria are interrelated a change in one criterion makes all other criteria change, too. 


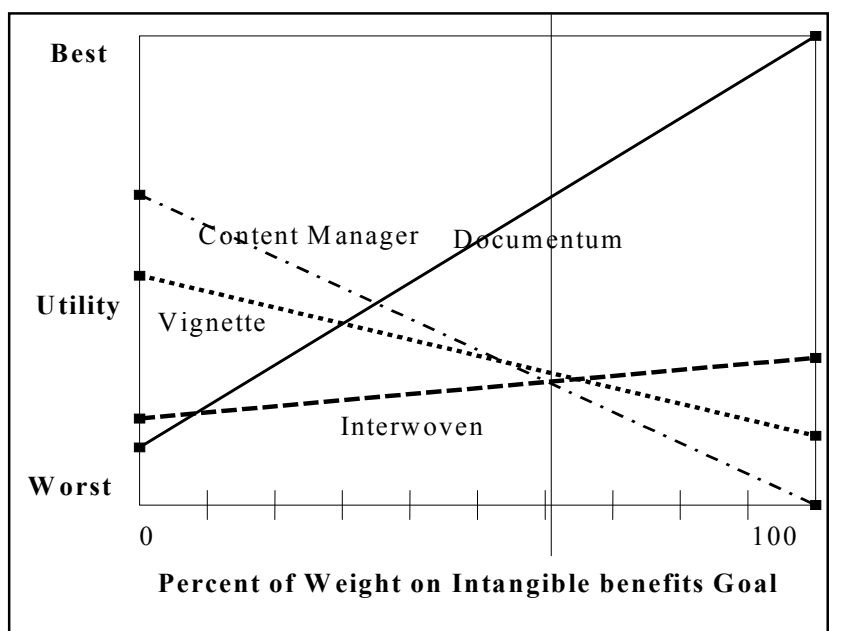

Figure 4. Sensitivity analysis for 'Intangible benefits'

Above the sensitivity analysis was performed only at the lowest level; priorities of strategies to inputs (see Table 1). We should, however, realize that the strategic investments have wider direct and indirect implications over the whole organization and the sensitivity of those organizational implications to input data should be evaluated or at least comprehended. If the formal sensitivity analysis is going to be extended also to the organizational effects then the goal hierarchy should be extended to cover wider organizational goals and objectives, too. Here, no such a formal analysis was made.

\section{Conclusion}

In this research we have proposed a theoretically sound framework for the evaluation of strategic IT investments, a methodology based on that framework, and a concrete investment support system to help decision makers. The framework covers at general level the inputs, outputs and the process of the strategic IT decision situation. In congruence with the framework a reduced AHP methodology was employed. Certainly, other multiattribute weighting techniques may also be used to implement the framework presented in this study. Furthermore, the methodology proposed here must, of course, be regarded as a supplement to other appraisal techniques. We believe, however, that making subjective and intangible issues explicit and allowing sensitivity analyses makes the methodology presented in this study valuable also from the practitioner point of view.

\section{References}

[1] Adler, R.W. (2000), "Strategic Investment Decision Appraisal Techniques: The Old and the New", Business Horizons, November-December 2000, 15-22.

[2] Banker R.D., Kauffman R.J. and Morey R.C. (1990), "Measuring Gains in Operational Efficiency from Information Technology: A Study of the Positran
Deployment at Hardee's Inc.", Journal of Management Information Systems, Vol.7, No.2 Fall 1990, 29-54.

[3] Barki, H., Rivard, S. and Talbot, J. (1993), "Toward an Assessment of Software Development Risk", Journal of Management Information Systems, Fall 1993, Vol. 10, No. 2, 203-225.

[4] Baroudi, J. J. and Orlikowski, W. J. (1988), "A ShortForm Measure of User Information Satisfaction: A Psychometric Evaluation and Notes on Use", Journal of Management Information Systems, 4, 44-59.

[5] Brynjolfsson, E. (1993), "The Productivity Paradox of Information Technology", Communication of $A C M, 36$, 67-77.

[6] Brynjolfsson, E. and Hitt, L.M. (1998), "Beyond the Productivity Paradox", Communications of the ACM, 41, $49-55$.

[7] Clemons E.K., Thatcher M.E. and Row M.C. (1995), "Identifying Sources of Reengineering Failures: A Study of the Behavioral Factors Contributing to Reengineering Risks", Journal of Management Information Systems, 12, 9-36.

[8] Clemons, E. K. (1991), "Investments in Information Technology", Communications of the ACM, 34, 23-36.

[9] Davern, M.J. and Kauffman, R.J. (2000), "Discovering potential and realizing value from information technology investments", Journal of Management Information Systems, Vol. 16, No. 4, Spring 2000, 121-143.

[10] Dickson, G. W. and Wetherbe, J.C., (1985), The Management of Information Systems, McGraw-Hill.

[11] Digital Planet, (2000) - The Global Information Economy. World Information Technology and Services Alliance (WITSA).

[12] Dos Santos, B.L. (1991), "Justifying Investments in New Technologies", Journal of Management Information Systems, 7, 71-90.

[13] Dose, J.J. (1997), "Work values: An integrative framework and illustrative application to organizational socialization", Journal of Occupational and Organizational Psychology, 70, 219-240.

[14] Farbey B., Land F. and Target D. (1992), "Evaluating investments in IT". Journal of Information Technology, 7, 109-122.

[15] Fritzsche, D.J. (1995), "Personal Values: Potential Keys to Ethical Decision Making”, Journal of Business Ethics, 14, 909-922.

[16] Garrity, E.J. and Sanders, G.L. (1998), "Information Systems Success Measurement", Idea Group Publishing

[17] Goodhue, D.L., Klein, B.D. and March, S.T. (2000), "User evaluations of IS as surrogates for objective performance", Information \& Management, Vol. 38, 87101.

[18] Gurbaxani V. and Whang S., (1991), "The Impact of Information Systems on Organizations and Markets", Communications of the ACM, Vol. 34, No. 1, 59-73.

[19] Hallikainen, P., Heikkilä, J., Peffers, K., Saarinen, T. and Wijnhoven, F. (1998), "Evaluating Information Technology Projects in Finland: Procedures, FollowThrough, Decision Making and Perceived Evaluation Quality", Journal of Global Information Management, Fall 1998, Vol. 6 No. 4.

[20] Heckman, R. (1999), "Managing the IT Procurement Process", Information Systems Management, Winter 1999, 61-71. 
[21] Hochstrasser, B. (1990), "Evaluating IT Investments: Matching Techniques and Projects", Journal of Information Technology, 5, 215-221.

[22] Irani, Z. and Love, P.E.D. (2001), “The Propagation of Technology Management Taxonomies for Evaluating Investments in Information Systems", Journal of Management Information Systems, Vol. 17, No. 3, Winter 2000-2001, 161-177.

[23] Ives, B. and Learmonth, G.P. (1984), "The Information System as a Competitive Weapon", Communications of the ACM, Vol. 27, No. 12, December 1984, 1193-1201.

[24] Kivijärvi, H. and Saarinen, S. (1995), "Investments in Information Systems and Financial Performance of the Firm", Information and Management, 28, 143-163.

[25] Kivijärvi, H. and Zmud, R. Z. (1993), "DSS Implementation Activities, Problem Domain Characteristics and DSS Success", European Journal of Information Systems, Vol.2, No. 3, 1993, 159-168.

[26] Lai, V.S., Trueblood, R.P. and Wong, B.K. (1999), "Software Selection: a Case Study of the Application of the Analytical Hierarchical Process to the Selection of a Multimedia Authoring System", Information \& Management, 36, 221-232.

[27] Lederer, A. and Mirani, R., (1995), "Anticipating the benefits of proposed information systems", Journal of Information Technology, Vol. 10, 159-169.

[28] Lyytinen, K., Mathiassen, L. and Ropponen, J. (1998), "Attention Shaping and Software Risk - A Categorical Analysis of Four Classical Risk Management Approaches", Information Systems Research, Vol. 9, No. 3, September 1998, 233-255.

[29] Marchewka, J.T. and Keil, M. (1995), "Portfolio Theory Approach For Selecting and Managing IT Projects", Information Resources Management Journal, Vol. 8, No. 4, Fall 1995, 5-14.

[30] Markowitz, H. (1952), "Portfolio Selection", Journal of Finance, March 1952, 77-91.

[31] Marshall, H. (1999), Sensitivity Analysis, in Dorf, R.C., Technology Management Handbook, CRC Press LLC.

[32] McIntyre, A. and Coulthurst, N. (1987), "The Planning and Control of Capital Investments in MediumSized UK-Companies", Management Accounting, Vol. 65, No. 3, 39-40.

[33] Menon, N.M., Lee, B., and Eldenburg, L. (2000), "Productivity of Information Systems in Healthcare Industry", Information Systems Research, Vol. 11, No. 1, 83-92.

[34] Mirani, R. and Lederer, A. (1998), “An Instrument for Assessing the Organizational Benefits of IS projects", Decision Sciences, Vol. 29, No. 4, Fall 1998, 803-838.

[35] Molnar, K.K. and Sharda, R. (1999), OSI-Based Model for the Justification of Telecommunications Investment: A Conceptual Framework, in Measuring Information Technology Investment Payoff: Contemporary Approaches, edited by Mahmood and Szewczak, Idea Group Publishing.

[36] Nonaka, S. and Takeuchi, N. 1995, The KowledgeCreating Company: How Japanese Companies Create the Dynamics of Innovation; Oxford University Press, New York.
[37] Pike, R. and Neale, B., (1996), Corporate Finance \& Investments - Decisions and Strategies, Prentice Hall.

[38] Powell P. (1992), "Information Technology Evaluation: Is It Different?", Journal of the Operational Research Society, 43, 29-42.

[39] Rokeach, M., (1973), The nature of human values, Free Press, New York.

[40] Saaty, T.L., (1980), The Analytic Hierarchy Process, McGraw-Hill, New York.

[41] Saaty, T.L. (1999), Decision Making for Leaders, RWS publications, Pittsburgh, PA.

[42] Santhanam, R. and Guimares, T. (1995), "Assessing the quality of institutional DSS". European Journal of Information Systems, 4, 159-170.

[43] Shank, J. (1996), Analysing Technology Investments - From NPV to Strategic Cost Management, Management Accounting Research, June 1996, 185-197

[44] Shapiro, A.C. (1991), Modern Corporate Finance, Macmillan Publishing Company.

[45] Smithson, S. and Hirschheim, R. (1998), "Analysing Information Systems Evaluation: Another Look at an Old Problem", European Journal of Information Systems, 1998, 7, 158-174.

[46] Tallon, P.P., Kraemer, K.L. and Gurbaxani, V. (2000), "Executives' perceptions of the business value of information technology: A process-oriented approach", Journal of Management Information Systems, Vol. 16, No. 4, Spring 2000, 145-173.

[47] Tam, K.Y. (1998), "The Impact of information Technology Investments on Firm Performance and Evaluation Evidence from Newly Industrialized Economics", Information Systems Research, 9(1), 85-98.

[48] Tushman, M.L. and Anderson, P. (1986), "Technological Discontinuities and Organizational Environments", Administrative Science Quarterly, 31, 439-465.

[49] Ward, J., Taylor, P. and Bond, P. (1996), "Evaluation and Realization of IS/IT benefits: an empirical study of current practice", European Journal of Information Systems, 4, 214-225.

[50] Wehrs, W.E. (1999), A Road Map for IS/IT Evaluation, in Measuring Information Technology Investment Payoff: Contemporary Approaches, edited by Mahmood and Szewczak, Idea Group Publishing.

[51] Weill, P. and Broadbent, M. (1998), Leveraging the New Infrastructure - How Market Leaders Capitalize on Information Technology, Harvard Business School Press.

[52] Weill, P. (1992), "The Relationship Between Investment in Information Technology and Firm Performance: A Study of the Valve Manufacturing Sector", Information Systems Research, Vol. 3, No. 4, 307-333.

[53] Wen, H.J. and Sylla, C. (1999), A Road Map for the Evaluation of Information Technology Investment, in Measuring Information Technology Investment Payoff: Contemporary Approaches, edited by Mahmood and Szewczak, Idea Group Publishing.

[54] Wiener, Y. (1988), "Forms Of Value Systems: A Focus On Organizational Effectiveness and Cultural Change and Maintenance", The Academy Of Management Review, Mississippi State, Vol. 13, No. 4, 534-545. 